\title{
Penerapan Metode Naive Bayes Untuk Klasifikasi Pelanggan
}

\author{
Hakam Febtadianrano Putro ${ }^{1)}$; Retno Tri Vulandari'2); Wawan LaksitoYuly Saptomo ${ }^{3)}$ \\ 1) 3) Program Studi Informatika, STMIK Sinar Nusantara \\ 2) Program Studi Teknologi Informasi, STMIK Sinar Nusantara \\ ${ }^{11)}$ hakamputro@gmail.com; ${ }^{2)}$ retnotv@sinus.ac.id; ${ }^{3)}$ wlaksito@sinus.ac.id
}

\begin{abstract}
Business location plays an important role in sales. The business location in cities makes the seller easier to distribute activities for people. Distribution activities are closely related to sales activities. If there is a sales transaction, a classification of potential and non-potential customers will be required. One method that can be used for classification is mining data. One of the most frequently used data mining for classification is the Naive Bayes method. The attributes used in the customer classification process are purchase amount, time interval, and location. The result of classification system are 23 true reactions and 2 false reactions. Based on the results are using the confusion matrix method, it shows that the accuracy value reaches $92 \%$, the precision value reaches $100 \%$, the recall value reaches $91 \%$.
\end{abstract}

Keywords: Trading Business, Customer Classification, Naive Bayes, Confusion Matrix

\section{PENDAHULUAN}

Usaha dagang di Sukoharjo semakin berkembang pesat. Semakin banyak pula usaha dagang dalam bidang penjualan ayam. Dengan adanya usaha dagang ini juga meliputi aspek yang bermanfaat bagi masyarakat sekitarnya.

Perkembangan teknologi yang terus berkembang membuat usaha dagang berlomba-lomba mencari terobosan baru

Permasalahan utama dalam usaha dagang ini masih kesulitan dalam mengolah data. Kurangnya pemanfaatan secara optimal dari banyaknya data transaksi untuk melihat pelanggan mana yang berpotensi atau tidak berpotensi.

Data mining merupakan salah satu teknik dalam pengolahan data yang menemukan hubungan dari data yang tidak diketahui oleh pengguna serta menyajikan nya kedalam bentuk yang mudah dipahami sehingga dari hubungan data tersebut dapat dijadikan sebagai dasar dalam pengambilan keputusan [1]. Data mining dibagi menjadi beberapa kelompok berdasarkan tugas yang dapat dilakukan yaitu : Deskripsi, Estimasi, Prediksi, Klasifikasi, Clustering, dan Asosiasi [2].

Secara singkat, klasifikasi merupakan pengelompokan objek kedalam kelas tertentu berdasarkan kelompoknya yang biasanya disebut dengan kelas (class). Salah satu metode klasifikasi yang sering digunakan adalah metode naive bayes. Berdasarkan penelitian yang telah dilakukan sebelumnya menggunakan metode naive bayes.
Metode naive bayes memiliki kelebihan, yaitu cepat dalam perhitungan, algoritma yang sederhana dan berakurasi tinggi [3]. Metode Naïve Bayes yang hanya membutuhkan jumlah data pelatihan (Training Data) yang kecil untuk menentukan estimasi parameter yang diperlukan dalam proses pengklasifikasian [4]. Metode Algoritma Naïve Bayes Casifier lebih mudah digunakan karena memiliki alur perhitungan yang tidak panjang [5]

Dari permasalahan tersebut maka menerapkan metode naïve bayes untuk mengklasifikasikan pelanggan. Adapun Tujuan dari penelitian ini adalah membuat aplikasi yang dapat membantu mengklasifikasikan pelanggan yang berpotensi dan tidak berpotensi, serta digunakan sebagai dasar pertimbangan keputusan salah satunya sebagai strategi pemasaran.

\section{TINJAUAN PUSTAKA \\ 2.1 Data Mining}

Data mining adalah serangkaian proses untuk menggali nilai tambah berupa informasi yang selama ini tidak diketahui secara manual dari suatu basis data. Informasi yang dihasilkan diperoleh dengan cara mengekstraksi dan mengenali pola yang penting atau mencari dari data yang terdapat pada basis data. Data mining terutama digunakan untuk mencari pengetahuan yang terdapat dalam basis data yang besar 
sehingga sering disebut Knowledge Discovery Databases (KDD) [6].

Klasifikasi merupakan suatu pekerjaan menilai objek data untuk memasukkannya ke dalam kelas tertentu dari sejumlah kelas yang tersedia. Dalam klasifikasi ada dua pekerjaan utama yang dilakukan, yaitu (1)Pembangunan model sebagai prototype untuk disimpan sebagai memori dan (2) Penggunaan model tersebut untuk melakukan pengenalan/klasifikasi/prediksi pada suatu objek data lain agar diketahui dikelas mana objek data tersebut dalam model yang sudah disimpannya [7].

\subsection{Personal Home Page Hipyertext Preprocessor (PHP)}

PHP merupakan bahasa berbentuk script yang ditempatkan dalam server dan diproses di server. PHP singkatan dari Hipyertext Preprocessor yaitu bahasa pemrograman web server-side yang bersifat open source [8]. Artinya semua sintaks yang diberikan akan sepenuhnya dijalankan pada server, sedangkan yang dikirimkan ke browser hanya hasilnya saja. PHP tergolong sebagai perangkat lunak open source yang diatur dalam aturan General Public License (GPL). PHP dirancang khusus untuk membentuk web dinamis, artinya PHP mampu menghasilkan website yang secara terus menerus hasilnya bisa berubah-ubah sesuai dengan pola yang diberikan. Hal ini berkaitan erat dengan basis data sebagai sumber data yang akan ditampilkan [9].

\subsection{Penelitian Terkait}

Penelitian tentang prediksi besarnya Penggunaan listrik rumah tangga. Tujuan dari penelitian ini mampu untuk memprediksi besarnya penggunaan listrik tiap rumah tangga agar lebih mudah mengatur penggunaan listrik. Variabel yang dipakai meliputi jumlah tanggungan keluarga, luas rumah, pendapatan/bulan, daya listrik, perlengkapan yang dimiliki. Metode yang dipakai menggunakan metode Naïve Bayes. Hasil dari penelitian ini persentase $78,3333 \%$ untuk keakuratan prediksi, di mana dari 60 data penggunaan listrik rumah tangga yang diuji terdapat 47 data penggunaan listrik rumah tangga yang berhasil diklasifikasikan dengan benar [10].

Penelitian tentang penerapan data mining pada penjualan barang menggunakan metode Naïve Bayes Classifier untuk optimasi strategi pemasaran. Tujuan dari penelitian ini untuk mengetahui minat dan ketertarikan calon pembeli terhadap produk yang tersedia. Variabel yang dipakai meliputi bulan, model barang, harga barang, terjual. Metode yang dipakai menggunakan metode Naïve Bayes. Hasil dari penelitian ini didapatkan nilai $\mathrm{p}$ value ( $\mathrm{sig}$ ), nilai $p$ value ( $\mathrm{sig}$ ) 0,807 $>0,05$ maka Ho diterima dan $\mathrm{Ha}$ ditolak, nilai thitung dan t-tabel, Nilai t-hitung - 0,246 > - ttabel -2,045 maka Ho diterima dan Ha ditolak [11].

Penelitian tentang penentuan penerima beasiswa bidikmisi Universitas Mulawarman. Tujuan dari penelitian ini untuk membantu bagian proses seleksi dengan membuat aplikasi perangkat lunak sistem pendukung keputusan untuk penentuan penerima beasiswa bidikmisi Universitas Mulawarman. Variabel yang dipakai meliputi pekerjaan orang tua, penghasilan orang tua, jumlah tanggungan, daya listrik(watt), dan nilai ujian nasional. Metode yang dipakai menggunakan metode Naïve Bayes. Hasil dari penelitian ini menghasilkan sebuah aplikasi sistem pendukung keputusan dengan tingkat akurasi sebesar $85.56 \%$ [12].

Penelitian tentang penentuan kelayakan pemilihan tempat tinggal. Tujuan dari penelitian ini untuk konsumen dalam mempertimbangkan penentuan pencarian tempat tinggal. Variabel dipakai meliputi keamanan, fasilitas umum, bebas banjir, harga, air bersih, model, sejuk dan nyaman. Metode yang dipakai menggunakan metode Naïve Bayes. Hasil dari penelitian ini menghasilkan probabilitas antara layak (sesuai) atau tidak sesuai, yang nantinya dapat digunakan oleh masyarakat umum untuk mempermudah dalam penentuan pencarian tempat tinggal [13].

Penelitian tentang klasifikasi kelayakan keluarga penerima beras rastra. Tujuan dari penelitian ini untuk mengatasi masalah yang belum optimal di desa Bandar Siantar Kecamatan Gunung Malela. Variabel yang dipakai meliputi Nama Kepala Rumah Tangga, PKH, Jml Tangungan, Kepala Rumah Tangga, Kondisi Rumah, Jml Penghasilan, Status Pemilik Rumah. Metode yang dipakai menggunakan metode Naïve Bayes. Hasil dari penelitian ini diharapkan dapat membantu pemerintah khususnya di daerah dalam menentukan kelayakan keluarga penerima beras Rastra [14]. 


\begin{abstract}
Bayesian classification adalah pengklasifikasian statistik yang dapat digunakan untuk memprediksi probabilitas keanggotaan suatu class. Bayes classification didasarkan pada teorema Bayes yang memiliki kemampuan klasifikasi serupa dengan decision tree dan neural network. Bayesian classification terbukti memiliki akurasi dan kecepatan yang tinggi saat diaplikasikan ke dalam database dengan data yang besar [15].
\end{abstract}

NBC merupakan salah satu algoritma klasifikasi yang sederhana namun memiliki kemampuan dan akurasi tinggi.

$$
P(C i \mid X)=\frac{P(X \mid C i) \cdot P(C i)}{P(X)}
$$

\section{dengan}

$X$ : data dengan class yang belum diketahui $\mathrm{Ci}$ : hipotesis data $\mathrm{X}$ merupakan suatu class spesifik

$\mathrm{P}(\mathrm{Ci} \mid \mathrm{X})$ :probabilitas hipotesis $\mathrm{Ci}$ berdasarkan kondisi X (posteriori probability)

$\mathrm{P}(\mathrm{Ci})$ : probabilitas hipotesis $\mathrm{Ci}$ (prior probability)

$\mathrm{P}(\mathrm{X} \mid \mathrm{Ci})$ : probabilitas $\mathrm{X}$ berdasrkan kondisi pada hipotesis $\mathrm{C}_{\mathrm{i}}$

$\mathrm{P}(\mathrm{X})$ : probabilitas dari $\mathrm{X}$

Naïve Bayesian Classifier mengasumsikan bahwa keberadaan sebah atribut (variabel) tidak ada kaitannya dengan beradaan atribut (variabel) yang lain karena asumsi atribut tidak saling terkait (conditionally independent), ditulis dengan rumus:

$$
\mathrm{P}(\mathrm{X} \mid \mathrm{Ci})=\sum_{\mathrm{k}=1}^{\mathrm{n}} \mathrm{P}(\mathrm{Xk} \mid \mathrm{Ci})
$$

Setelah diperoleh hasil dari seluruh data pada setiap class, maka hasil akhirnya dapat menggunakan rumus:

$$
\mathrm{P}(\mathrm{X} \mid \mathrm{Ci})=\arg \max \mathrm{P}(\mathrm{Xi} \mid \mathrm{Ci}) * \mathrm{P}(\mathrm{Ci})
$$

\section{METODE PENELITIAN}

Dalam penyusunan penelitian ini diperlukan metode-metode penelitian dalam proses pengumpulan data antara lain:

\subsection{Sumber Data}

\section{a. Data Primer}

Data primer diperoleh dari hasil kegiatan pengumpulan data terhadap data transaksi penjualan ayam. b. Data Sekunder

Data sekunder dalam penelitian ini melakukan pengolahan data dari data laporan penjualan ayam untuk menentukan kriteria status usaha, jumlah pembelian, dan lokasi. Selain itu untuk menunjang data pendukung yang diperoleh dari media pustaka tentang teori-teori yang digunakan dalam penelitian ini. Adapun data sekunder yang diantaranya Data Mining, Klafikasi, Naïve Bayes, MySQL, PHP, UML, Kajian Pustaka.

\subsection{Metode Pengumpulan Data}

a. Metode Observasi, dalam penelitian ini dilakukan pengamatan terhadap prosedur penjualan ayam.

b. Metode Wawancara, menanyakan langsung kepada pemilik UD.Samodro untuk mendapatkan data yang akan diteliti untuk menyesuaikan proses data yang akan diolah menggunakan metode Naïve Bayes.

c. Studi Pustaka, terdiri dari literatur mengenai penelitian yang sedang dilakukan. Literatur yang dimaksud diantaranya beberapa jurnal ilmiah dan buku yang terkait dengan kasus penelitian ini. Adapun jurnal ilmiah dan buku yang dijadikan sebagai acuan.

\subsection{Metode Pengembangan Sistem}

a. Perancangan Sistem

Perancangan sistem dalam penelitian ini menggunakan UML diharapkan pengerjaan bahasa visual yang lebih jelas dan terstruktur baik user yang digunakan.

b. Kontruksi Sistem

Kontruksi sistem dalam penelitian ini penunjang pembuatan sebuah aplikasi yang saling berkaitan, yaitu perangkat keras(hardware), perangkat lunak (software).

c. Pengujian Sistem

Proses selanjutnya pengujian aplikasi yang telah dibuat akan diuji untuk mengetahui apakah aplikasi yang dibuat sudah berjalan dengan dan sesuai perancangan yang dilakukan.

\section{HASIL DAN PEMBAHASAN \\ 4.1 Klasifikasi Pelanggan}

Data latih dan data uji yang digunakan untuk klasifikasi berjumlah 75 data latih dan 
25 data uji, dimana data latih selanjutnya akan proses menggunakan metode naive bayes. Adapun data latih yang digunakan dapat dilihat pada Tabel 1.

Tabel 1. Data Latih

\begin{tabular}{|c|c|c|c|c|}
\hline $\begin{array}{c}\text { Kode } \\
\text { Pelanggan }\end{array}$ & $\begin{array}{c}\text { Jumlah } \\
\text { Pembelian }\end{array}$ & $\begin{array}{l}\text { Interval } \\
\text { Waktu }\end{array}$ & Lokasi & Target \\
\hline $\mathrm{P} 1$ & $\begin{array}{l}\text { Sangat } \\
\text { Banyak }\end{array}$ & Harian & Dekat & Berpotensi \\
\hline P2 & $\begin{array}{l}\text { Sangat } \\
\text { Banyak }\end{array}$ & Harian & Jauh & Berpotensi \\
\hline P3 & $\begin{array}{l}\text { Sangat } \\
\text { Sedikit }\end{array}$ & Mingguan & Jauh & $\begin{array}{c}\text { Tidak } \\
\text { Berpotensi }\end{array}$ \\
\hline P4 & $\begin{array}{l}\text { Sangat } \\
\text { Sedikit }\end{array}$ & Mingguan & Dekat & $\begin{array}{c}\text { Tidak } \\
\text { Berpotensi }\end{array}$ \\
\hline P5 & Banyak & Harian & Jauh & Berpotensi \\
\hline P6 & Banyak & Harian & Dekat & Berpotensi \\
\hline P7 & $\begin{array}{l}\text { Sangat } \\
\text { Sedikit }\end{array}$ & Mingguan & Dekat & $\begin{array}{c}\text { Tidak } \\
\text { Berpotensi }\end{array}$ \\
\hline P8 & $\begin{array}{l}\text { Sangat } \\
\text { Sedikit }\end{array}$ & Mingguan & Dekat & $\begin{array}{c}\text { Tidak } \\
\text { Berpotensi }\end{array}$ \\
\hline P9 & Banyak & Harian & Jauh & Berpotensi \\
\hline $\mathrm{P} 10$ & Banyak & Harian & Jauh & Berpotensi \\
\hline $\mathrm{P} 11$ & Sedikit & Harian & Dekat & Berpotensi \\
\hline P21 & Sedikit & Harian & Dekat & Berpotensi \\
\hline P31 & $\begin{array}{l}\text { Sangat } \\
\text { Sedikit }\end{array}$ & Harian & Jauh & $\begin{array}{c}\text { Tidak } \\
\text { Berpotensi }\end{array}$ \\
\hline P41 & $\begin{array}{l}\text { Sangat } \\
\text { Banyak }\end{array}$ & Harian & Dekat & Berpotensi \\
\hline P51 & $\begin{array}{l}\text { Sangat } \\
\text { Sedikit }\end{array}$ & Mingguan & Jauh & $\begin{array}{c}\text { Tidak } \\
\text { Berpotensi }\end{array}$ \\
\hline P61 & Sedikit & Harian & Dekat & Berpotensi \\
\hline P71 & Sedikit & Mingguan & Dekat & Berpotensi \\
\hline P75 & $\begin{array}{l}\text { Sangat } \\
\text { Banyak }\end{array}$ & Harian & Dekat & Berpotensi \\
\hline
\end{tabular}

Data yang dipakai sebagai data latih dan uji menggunakan data pada tahun 2019 yang dapat dilihat pada Tabel 2.

Tabel 2. Komposisi Data Latih \& Data Uji

\begin{tabular}{|l|c|ll|}
\hline Jenis Data & Jumlah & \multicolumn{3}{|c|}{ Keterangan } \\
\hline Data Latih & 75 & $\begin{array}{l}\text { Penjualan pada Bulan Juni - } \\
\text { Agustus }\end{array}$ \\
\hline Data Uji & 25 & $\begin{array}{l}\text { Penjualan pada Bulan Juni - } \\
\text { Agustus }\end{array}$ \\
\hline
\end{tabular}

Adapun nilai probabilitas setiap kriteria yang didapatkan dari data latih pada Tabel 1 . Ditentukan nilai probabilitas dari setiap kriteria kedalam kategori, yaitu :

a. Probabilitas jumlah pembelian pada setiap class, seperti pada Tabel 3.

Tabel 3. Probabilitas Jumlah Pembelian

\begin{tabular}{|c|c|c|c|c|}
\hline \multirow{2}{*}{$\begin{array}{l}\text { Jumlah } \\
\text { Pem- } \\
\text { belian }\end{array}$} & \multicolumn{2}{|c|}{$\begin{array}{l}\text { Jumlah kejadian } \\
\text { "Jumlah Pembelian" }\end{array}$} & \multicolumn{2}{|c|}{ Probabilitas } \\
\hline & $\begin{array}{c}\text { Berpo- } \\
\text { tensi }\end{array}$ & $\begin{array}{c}\text { Tidak } \\
\text { Berpotensi }\end{array}$ & $\begin{array}{l}\text { Berpo- } \\
\text { tensi }\end{array}$ & $\begin{array}{c}\text { Tidak } \\
\text { Berpotensi }\end{array}$ \\
\hline $\begin{array}{l}\text { Sangat } \\
\text { Banyak }\end{array}$ & $19 / 55$ & $0 / 20$ & 0,34 & 0 \\
\hline Banyak & $18 / 55$ & $0 / 20$ & 0,33 & 0 \\
\hline Sedikit & $17 / 55$ & $2 / 20$ & 0,31 & 0,1 \\
\hline $\begin{array}{l}\text { Sangat } \\
\text { Sedikit }\end{array}$ & $1 / 55$ & $18 / 20$ & 0,02 & 0,9 \\
\hline
\end{tabular}

b. Probabilitas interval waktu pada setiap class , seperti pada Tabel 4.

Tabel 4. Probabilitas Interval Waktu

\begin{tabular}{|c|c|c|c|c|}
\hline \multirow{2}{*}{$\begin{array}{c}\text { Interval } \\
\text { Waktu }\end{array}$} & \multicolumn{2}{|c|}{$\begin{array}{c}\text { Jumlah kejadian } \\
\text { "Interval Waktu" }\end{array}$} & \multicolumn{2}{c|}{ Probabilitas } \\
\cline { 2 - 5 } & $\begin{array}{c}\text { Berpo- } \\
\text { tensi }\end{array}$ & $\begin{array}{c}\text { Tidak } \\
\text { Berpotensi }\end{array}$ & Berpotensi & $\begin{array}{c}\text { Tidak } \\
\text { Berpotensi }\end{array}$ \\
\hline Harian & $53 / 55$ & $3 / 20$ & 0,95 & 0,15 \\
\hline Mingguan & $3 / 55$ & $17 / 20$ & 0,05 & 0,85 \\
\hline
\end{tabular}

c. Probabilitas lokasi pada setiap class, seperti pada Tabel 5.

Tabel 5. Probabilitas Lokasi

\begin{tabular}{|l|c|c|c|c|}
\hline \multirow{2}{*}{ Lokasi } & \multicolumn{2}{|c|}{$\begin{array}{c}\text { Jumlah kejadian } \\
\text { "Lokasi" }\end{array}$} & \multicolumn{2}{c|}{ Probabilitas } \\
\cline { 2 - 5 } & Berpotensi & $\begin{array}{c}\text { Tidak } \\
\text { Berpotensi }\end{array}$ & Berpotensi & $\begin{array}{c}\text { Tidak } \\
\text { Berpotensi }\end{array}$ \\
\hline Dekat & $39 / 55$ & $7 / 20$ & 0,71 & 0,35 \\
\hline Jauh & $16 / 55$ & $13 / 20$ & 0,29 & 0,65 \\
\hline
\end{tabular}

d. Probabilitas target pada setiap class, seperti pada Tabel 6.

Tabel 6. Probabilitas Target

\begin{tabular}{|c|c|c|c|}
\hline \multicolumn{2}{|c|}{ Jumlah Kejadian "Target" } & \multicolumn{2}{c|}{ Probabilitas } \\
\hline Berpotensi & $\begin{array}{c}\text { Tidak } \\
\text { Berpotensi }\end{array}$ & Berpotensi & Tidak Berpotensi \\
\hline $55 / 75$ & $20 / 75$ & 0,73 & 0,27 \\
\hline
\end{tabular}

\subsection{Pengujian Metode Naive Bayes Menggunakan Data Testing}

Setelah proses klasifikasi menggunakan metode naive bayes selesai, selanjutnya pengujian data uji yang berjumlah 25 data pelanggan dapat dilihat pada Tabel 7.

\section{Tabel 7. Data Uji}

\begin{tabular}{|c|c|c|c|c|}
\hline $\begin{array}{c}\text { Kode } \\
\text { Pelanggan }\end{array}$ & $\begin{array}{c}\text { Jumlah } \\
\text { Pembelian }\end{array}$ & $\begin{array}{c}\text { Interval } \\
\text { Waktu }\end{array}$ & Lokasi & $\begin{array}{c}\text { Prediksi } \\
\text { Target }\end{array}$ \\
\hline P76 & Banyak & Harian & Dekat & Berpotensi \\
\hline P77 & Sedikit & Mingguan & Dekat & Berpotensi \\
\hline P78 & Banyak & Harian & Jauh & Berpotensi \\
\hline P79 & Banyak & Harian & Jauh & Berpotensi \\
\hline P80 & Banyak & Harian & Dekat & Berpotensi \\
\hline P81 & Sedikit & Harian & Dekat & Berpotensi \\
\hline P82 & $\begin{array}{l}\text { Sangat } \\
\text { Banyak }\end{array}$ & Harian & Dekat & Berpotensi \\
\hline P83 & Sedikit & Harian & Jauh & Berpotensi \\
\hline P84 & $\begin{array}{l}\text { Sangat } \\
\text { Banyak }\end{array}$ & Harian & Dekat & Berpotensi \\
\hline P85 & Banyak & Harian & Dekat & Berpotensi \\
\hline P86 & $\begin{array}{l}\text { Sangat } \\
\text { Banyak }\end{array}$ & Harian & Dekat & Berpotensi \\
\hline P87 & Banyak & Harian & Dekat & Berpotensi \\
\hline P88 & $\begin{array}{l}\text { Sangat } \\
\text { Sedikit }\end{array}$ & Mingguan & Jauh & $\begin{array}{c}\text { Tidak } \\
\text { Berpotensi }\end{array}$ \\
\hline P89 & Banyak & Harian & Jauh & Berpotensi \\
\hline P90 & Sedikit & Mingguan & Dekat & Berpotensi \\
\hline P91 & Sedikit & Mingguan & Dekat & Berpotensi \\
\hline P92 & $\begin{array}{l}\text { Sangat } \\
\text { Sedikit }\end{array}$ & Harian & Dekat & $\begin{array}{c}\text { Tidak } \\
\text { Berpotensi }\end{array}$ \\
\hline P93 & $\begin{array}{l}\text { Sangat } \\
\text { Sedikit }\end{array}$ & Harian & Dekat & $\begin{array}{c}\text { Tidak } \\
\text { Berpotensi }\end{array}$ \\
\hline P94 & $\begin{array}{l}\text { Sangat } \\
\text { Sedikit }\end{array}$ & Mingguan & Dekat & $\begin{array}{c}\text { Tidak } \\
\text { Berpotensi }\end{array}$ \\
\hline P95 & $\begin{array}{l}\text { Sangat } \\
\text { Banyak }\end{array}$ & Harian & Dekat & Berpotensi \\
\hline P96 & Banyak & Harian & Dekat & Berpotensi \\
\hline P97 & Sedikit & Mingguan & Dekat & Berpotensi \\
\hline P98 & Banyak & Harian & Jauh & Berpotensi \\
\hline P99 & Banyak & Harian & Jauh & Berpotensi \\
\hline P100 & Banyak & Harian & Dekat & Berpotensi \\
\hline
\end{tabular}


Hasil klasifikasi yang disajikan pada Tabel 8, maka selanjutnya dapat dikonversikan menggunakan metode confusion matrix seperti bawah ini :

Tabel 8. Pengujian Conffusion Matrix

\begin{tabular}{|c|c|c|c|}
\hline \multirow{2}{*}{ Confusion Matrix } & \multicolumn{3}{|c|}{ Data Sebenarnya } \\
\cline { 2 - 4 } & \multicolumn{2}{|c|}{ TRUE } & FALSE \\
\hline \multirow{2}{*}{ Data Prediksi } & TRUE & 21 & 0 \\
\cline { 2 - 4 } & FALSE & 2 & 2 \\
\hline
\end{tabular}

Dari tabel confusion matrix diatas maka kinerja dari penggunaan metode naive bayes dapat diukur dengan menghitung nilai precision, recall, acuracy. Dalam perhitungan ini sekaligus dikonversikan kedalam bentuk presentase.

a). Maka untuk menghitung nilai precision menggunakan rumus (1), hasil perhitungan sebagai berikut :

Nilai Precision $=21 /(21+0) \quad=100 \%$

b). Maka untuk menghitung nilai recall menggunakan rumus (2.1), hasil perhitungan sebagai berikut :

Nilai Recall $=21 /(21+2) \quad=91 \%$

c). Maka untuk menghitung nilai acuracy menggunakan rumus (2.1), hasil perhitungan sebagai berikut :

Nilai Accuracy $=21+2 /(21+2+0+2)=92 \%$

\section{PENUTUP}

\subsection{Kesimpulan}

Berdasarkan penelitian tentang klasifikasi pelanggan menggunakan metode naive bayes dapat ditarik kesimpulan dari beberapa kesimpulan sebagai berikut:

1. Penerapan metode naive bayes untuk mengklasifikasikan pelanggan dapat membantu pemilik memberikan bonus terhadap pelanggan berpotensi dan meningkat kualitas yang lebih baik lagi terhadap pelanggan.

2. Aplikasi metode naive bayes untuk mengklasifikasikan pelanggan dirancang dengan menggunakan aplikasin PHP dan MySQL.

3. Berdasarkan master pelanggan yang dijadikan data latih, telah berhasil mengklasifikasikan 23 data dari 25 data yang diuji. Sehingga berhasil memprediksi pelanggannya dengan nilai precision mencapai $100 \%$, nilai recall mencapai $91 \%$, nilai accuracy mencapai $92 \%$.

\subsection{Saran}

Saran yang dapat dituliskan untuk penelitian ini adalah sebagai berikut: Sistem yang dibuat masih cukup sederhana karena mengutamakan proses perhitungan dan hasil perhitungan sehingga diharapkan sistem dikembangkan lebih detail.

\section{DAFTAR PUSTAKA}

[1] M. Ridwan, H. Suyono and M. Sarosa, "Penerapan Data Mining untuk Evaluasi Kinerja Akademik Mahasiswa menggunakan Algoritma Naïve Bayes Classifier," EECCIS, vol. VII, 2013.

[2] W. Muslehatin, M. Ibnu and Mustakim. , "Penerapan Naïve Bayes Classification untuk Klasifikasi Tingkat Kemungkinan Obesitas Mahasiswa Sistem Informasi UIN Suska Riau," 2017.

[3] H. Muhamad, C. Prasojo, N. Sugianto, L. Surtiningsih and I. Cholissodin, "Optimasi Naïve Bayes Classifier dengan Menggunakan Particle Swarm Optimization pada Data Iris," Jurnal Teknologi Informasi dan IImu Komputer (JTIIK), vol. IV, pp. 180-184, 2017.

[4] E. Manulu, F. Sianturi and M. Manulu, "Penerapan Algoritma Naïve Bayes untuk Memprediksi Jumlah Produksi Barang Berdasarkan Data Persediaan dan Jumlah Pemesanan PASTRIES," Jurnal Mantik Penusa, vol. I, 2017.

[5] T. Rosandy, "Perbandingan Metode Naïve Bayes Classifier dengan Metode Decision Tree (C4.5) untuk Menganalisa Kelancaran Pembiayaan (Studi Kasus : KSPPS/BMT Al-Fadhila)," Jurnal TIM Darmajaya, vol. II, p. 52, 2016.

[6] Vulandari, Data Mining Teori dan Aplikasi Rapidminer, Yogyakarta: Gava Media, 2017.

[7] E. Prasetyo, Data Mining Konsep dan Aplikasi Menggunakan MATLAB, Yogyakarta: ANDI , 2012.

[8] Anhar. Panduan Menguasai PHP \& MySQL Secara Otodidak, jakarta: Mediakita, 2010.

[9] S. Faisal, Aplikasi Berbasis Web dengan PHP \& MySQL, Yogyakarta: Ram Media, 2011.

[10] A. Saleh, "Implementasi Metode Naive Bayes Dalam Memprediksi Besarnya Penggunaan Listrik Rumah Tangga," 
Citec Journal, 2015.

[11] O. Nurdiawan and N. Salim, "Penerapan Data Mining Pada Penjualan Barang Menggunakan Metode Naïve Bayes Classifier Untuk Optimasi Strategi Pemasaran," Jurnal Teknologi Informasi dan Komunikasi, 2018.

[12] D. Dahri, F. Agus and D. Khairina, "Metode Naïve Bayes Untuk Penentuan Penerima Beasiswa Bidikmisi Universitas Mulawarman," Jurnal Informatika Mulawarman, 2016.

[13] D. Fithri, "Model Data Mining Dalam Penentuan Kelayakan Pemilihan Tempat Tinggal Menggunakan Metode Naïve Bayes," Jurnal SIMETRIS, 2016.

[14] C. Fadlan, S. Ningsih and A. Windarto, "Penerapan Metode Naïve Bayes Dalam Klasifikasi Kelayakan Keluarga Penerima Beras Rastra," JUTIM, 2018.

[15] Kusrini. and E. Luthfi, Algoritma Data Mining, Yogyakarta: ANDI, 2019. 